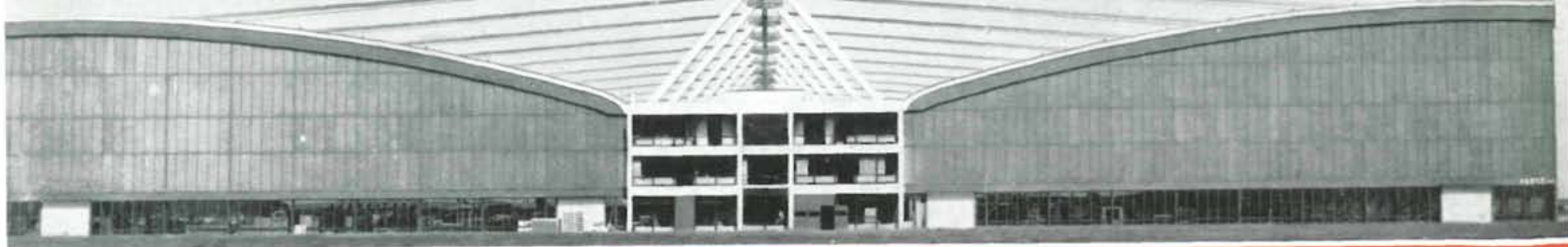

\title{
hangar en el aeropuerto de Frankfur-am-Main
}

$545 \cdot 29$

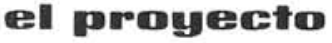

Los proyectistas del hangar de Frankfur - am - Main (Alemania) se aprovecharon de las experiencias americanas a este respecto. Se eligió un tipo de hangar que cuenta con un cuerpo central de hormigón armado, de $22 \mathrm{~m}$ de ancho, $10 \mathrm{~m}$ de altura ( 3 plantas) y $171 \mathrm{~m}$ de longi. tud. Al sur y norte se forman naves, de $55 \times 156 \mathrm{~m}$ en planta, para albergue de los aviones. Bajo la parte central se hallan los sótanos para el aprovisionamiento y depósitos.

\section{el thangar}

El hangar está constituido por una estructura de hormigón, compuesta, en su cubierta, por nervios plegados, de sección en forma de $\mathrm{V}$, formando lucernario en la unión entre dos con secutivos de ellos. Estos nervios se han espaciado a $10,68 \mathrm{~m}$, y descan san, en su arranque, en el cuerpo central, y la otra extremidad, for mando ménsula, se suspende con cables apoyados en torres que se elevan sobre el cuerpo central del han gar. La altura de estos nervios, en arranques, es de $10 \mathrm{~m}$, y de $16 \mathrm{~m}$ en su extremidad en voladizo. El es pesor de los nervios varía de 8 a 12 metros.

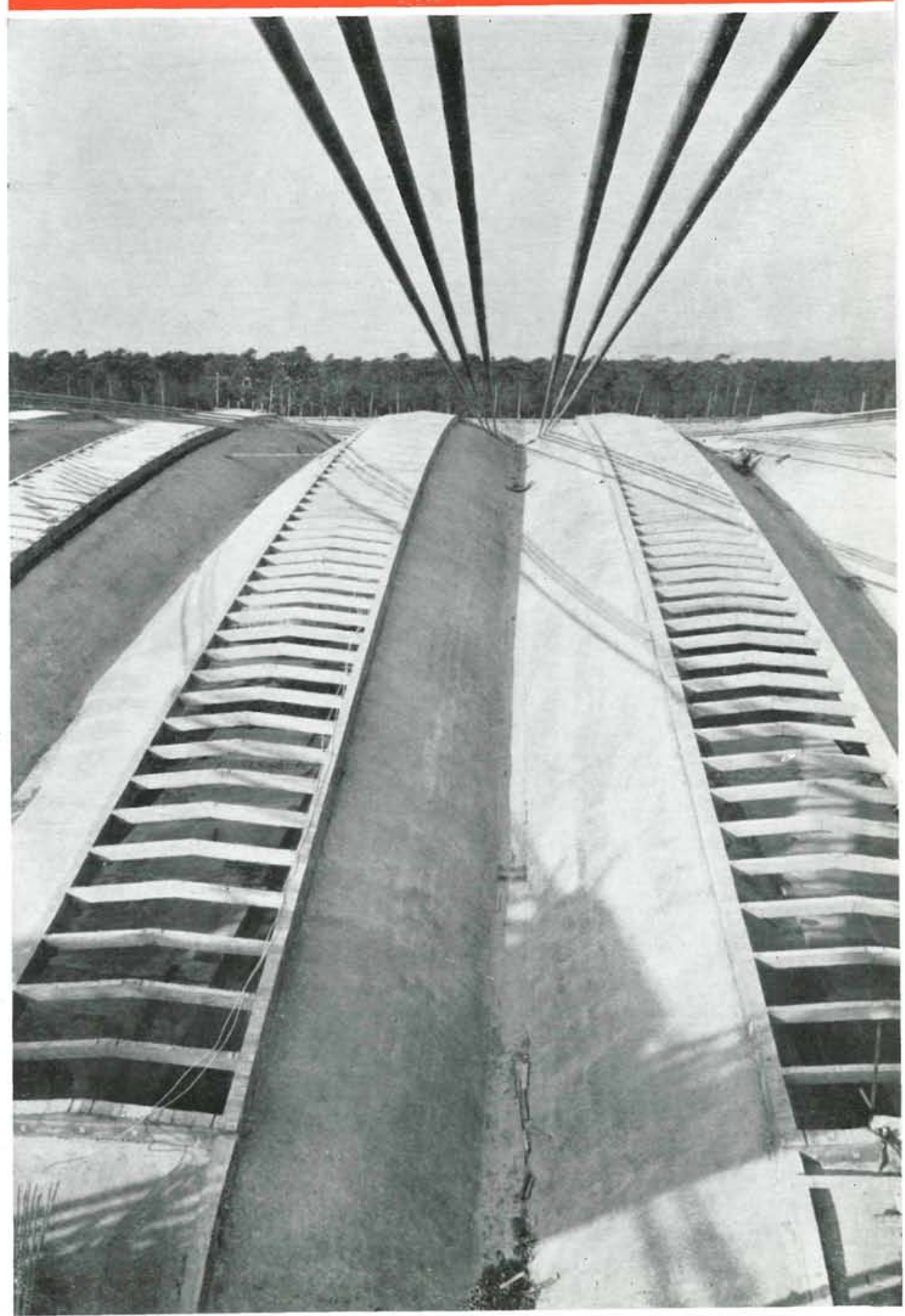




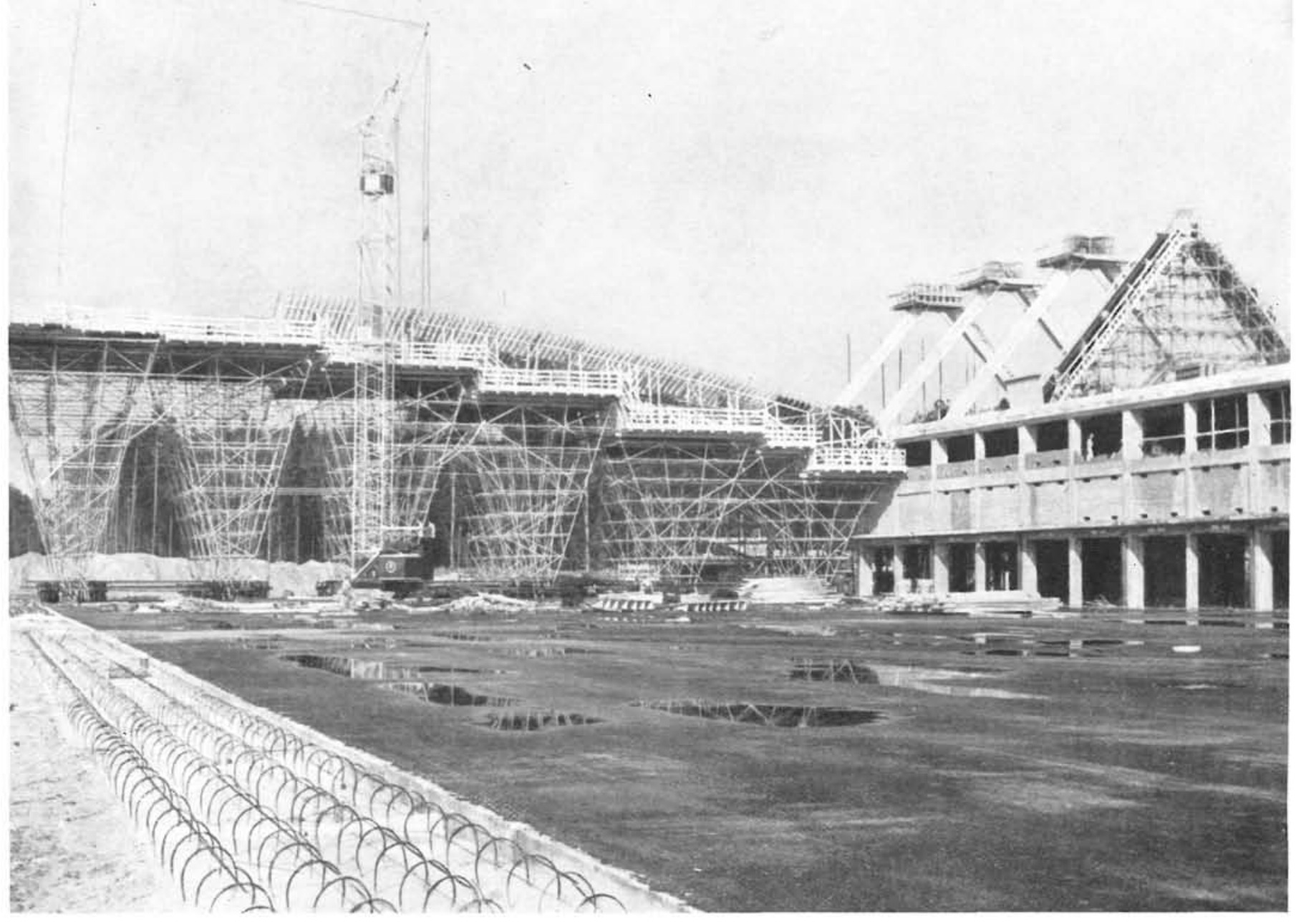

El cuerpo central está constituido por una estructura de hormigón armado, de tres plantas, que se extiende hasta el sótano, donde se ha aislado convenientemente contra la humedad.

En la parte superior de este cuerpo central se han levantado las torres, también de hormigón armado, en forma de $\mathrm{V}$ invertida, en cuyo vértice superior se han construido las sillas para apoyo de los cables de suspensión de las dos ménsulas formadas a una y otra parte del cuerpo central. Estas torres se han arriostrado por medio de una especie de caballete que une a cuatro vértices consecutivos, lo cual da lugar a la formación de tramos independientes.

Los nervios, provistos de los lucernarios correspondientes, son de hormigón armado, arrancan en el cuerpo central, reforzado, y se extienden al exterior en forma de ménsula, de cuya extremidad arrancan los cables de suspensión en ella anclados.

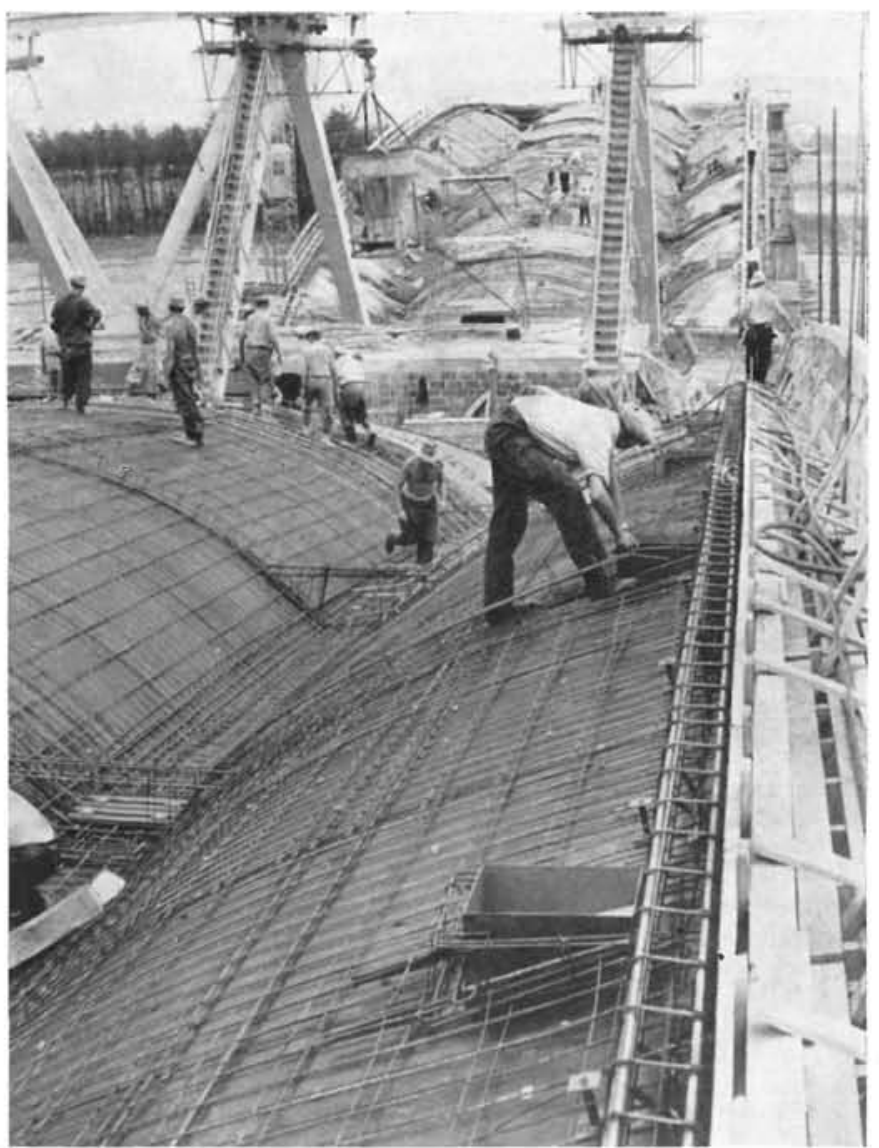




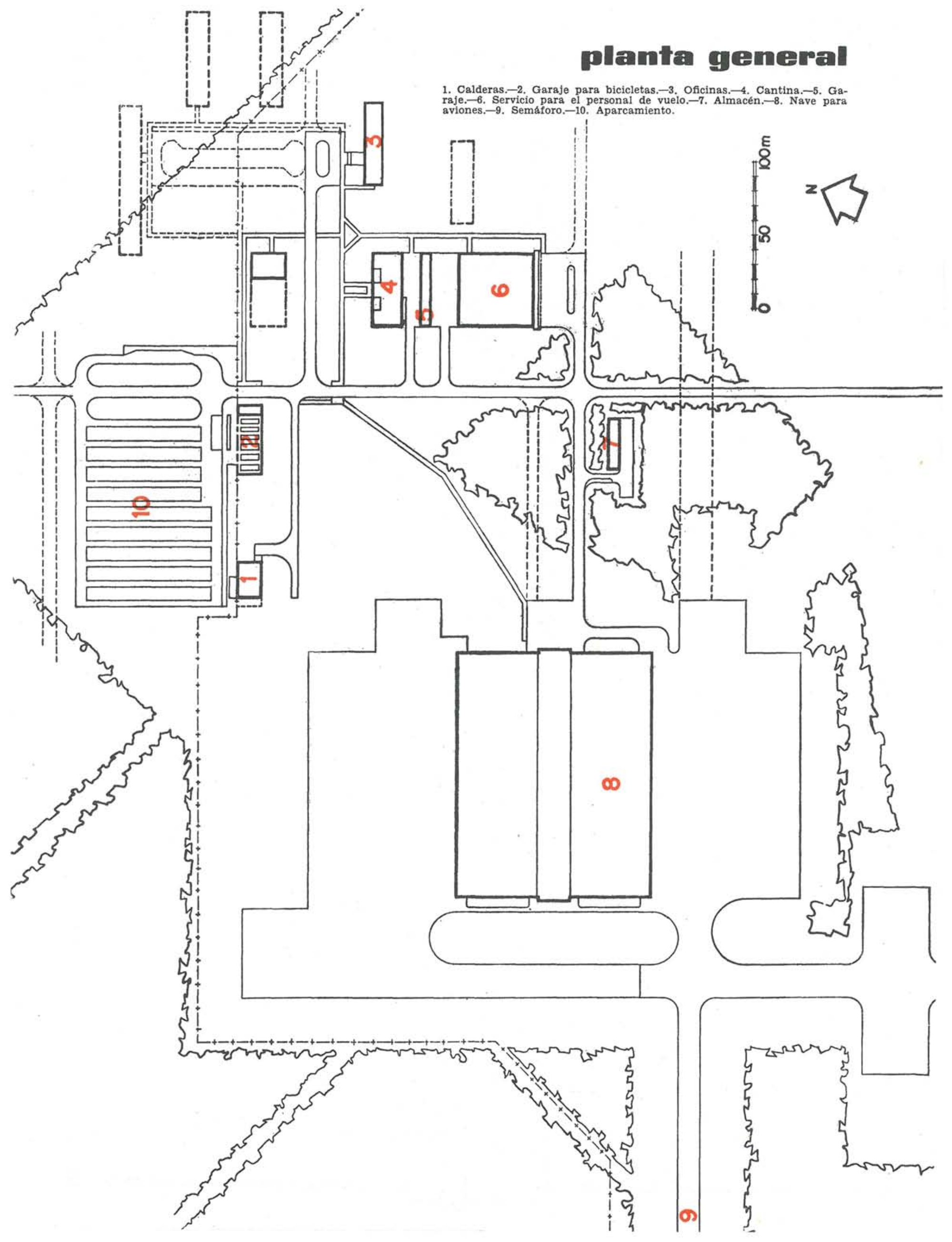


1. Junta de dilatación. -2 . Junta de repartición. -3 . Taller para pintura. -4 . Departamento para limpieza.-5. Taller mecanico. - 6. Taller para cerrajeria. - 7. Taller para caldereria. - 8. Almacen para herramientas. -9 . W. C. caballeros. terí - 16. Reservado - 17. Taller p. de talleres - 21 26. Sals para tramiento-27. móvil,-32. Almacén.-33. Depósito para instrumentos.-34. Almacén para la aduana.-35. Recepción de mercancías.

planta baja

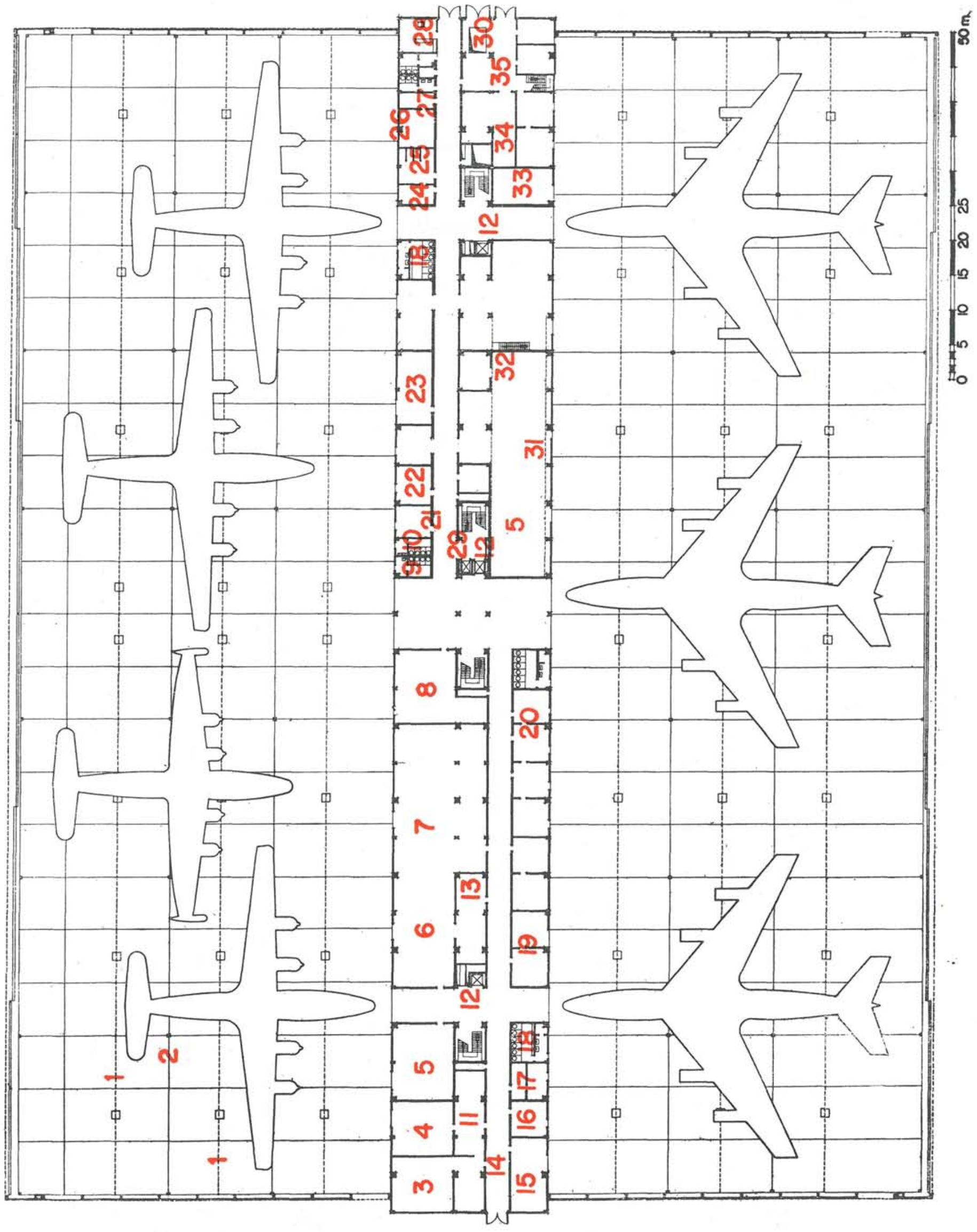


planta

de sótano
1. Pozos para suministro de agua, aire comprimido y electricidad. -2 . Túnel para cables. -3 . Instalaciones.-4. Ascensor,-5. Conductos para calefacción.-6. Distribución de ag tas, -7 . Distribución de calefacción.-8. Rampa.-9, Montacargas.-10. Almacén.-11, Compresores.-12. Pasillo.-13. Cuadro para distribucion electrica.-14. Toma de aire.-15. Transformadores.-16. Suministro para bombas.17. Almacén para aceite y petróleo,-18. Toma de aceite.

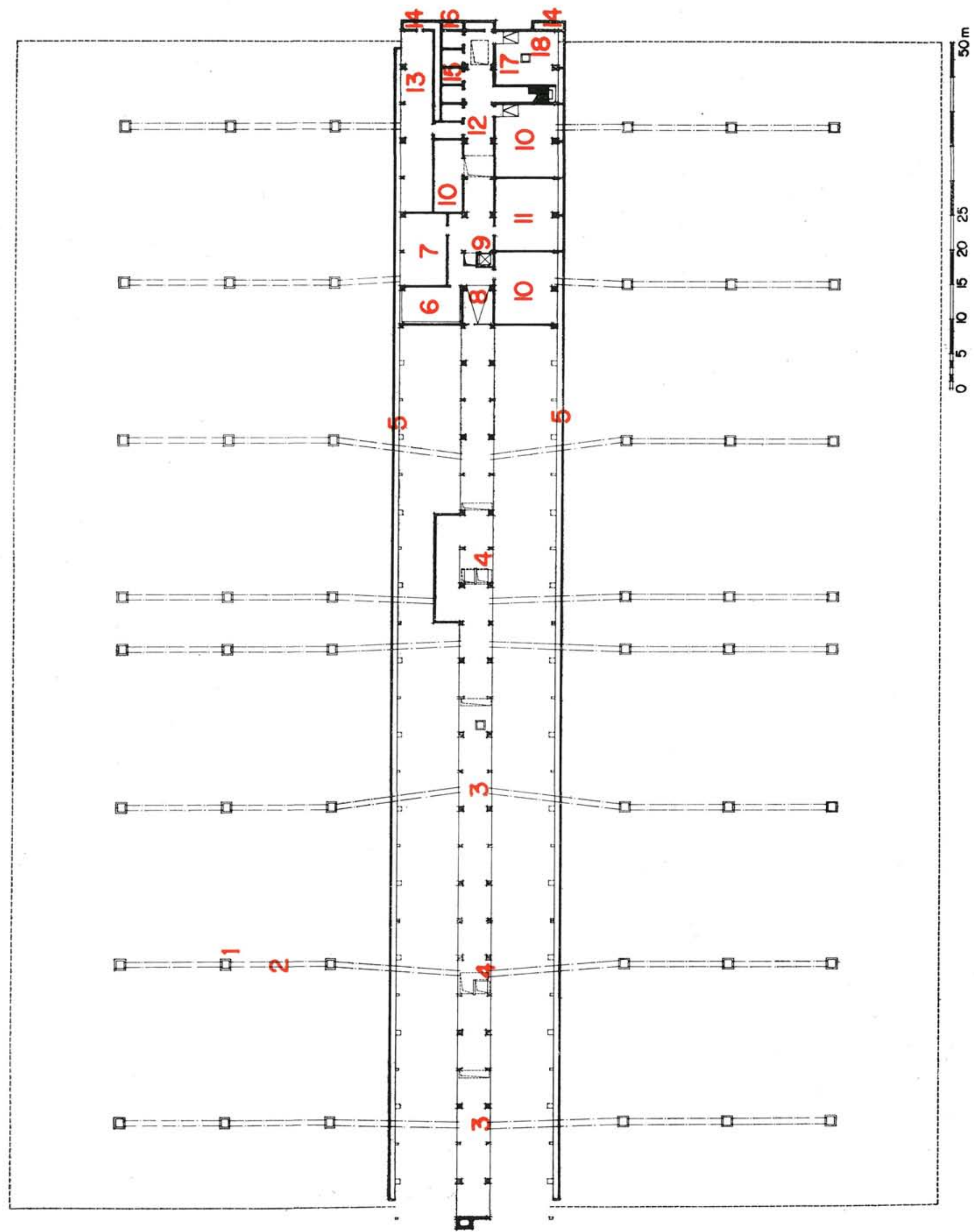




\section{Seceín}

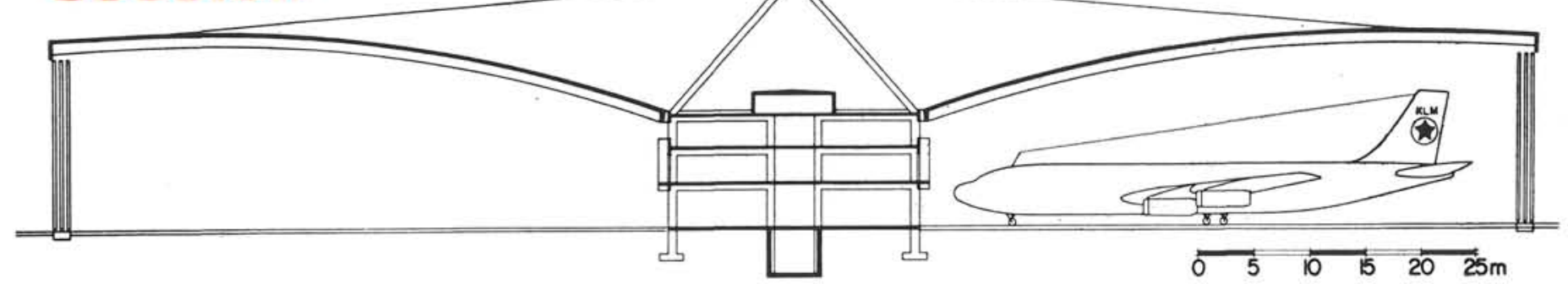

Para su construcción y hormigonado "in situ» se utilizaron entramados tubulares metálicos montados sobre mesillas móviles que corrían a lo largo de una serie de vías. Esta disposición permitió se pudieran hormigonar por tramos independientes, y al desencofrar poderlos trasladar a su nueva posición para iniciar la construcción de un nuevo tramo, operación que, dada la instalación auxiliar de vías, se realizaba con suma facilidad.

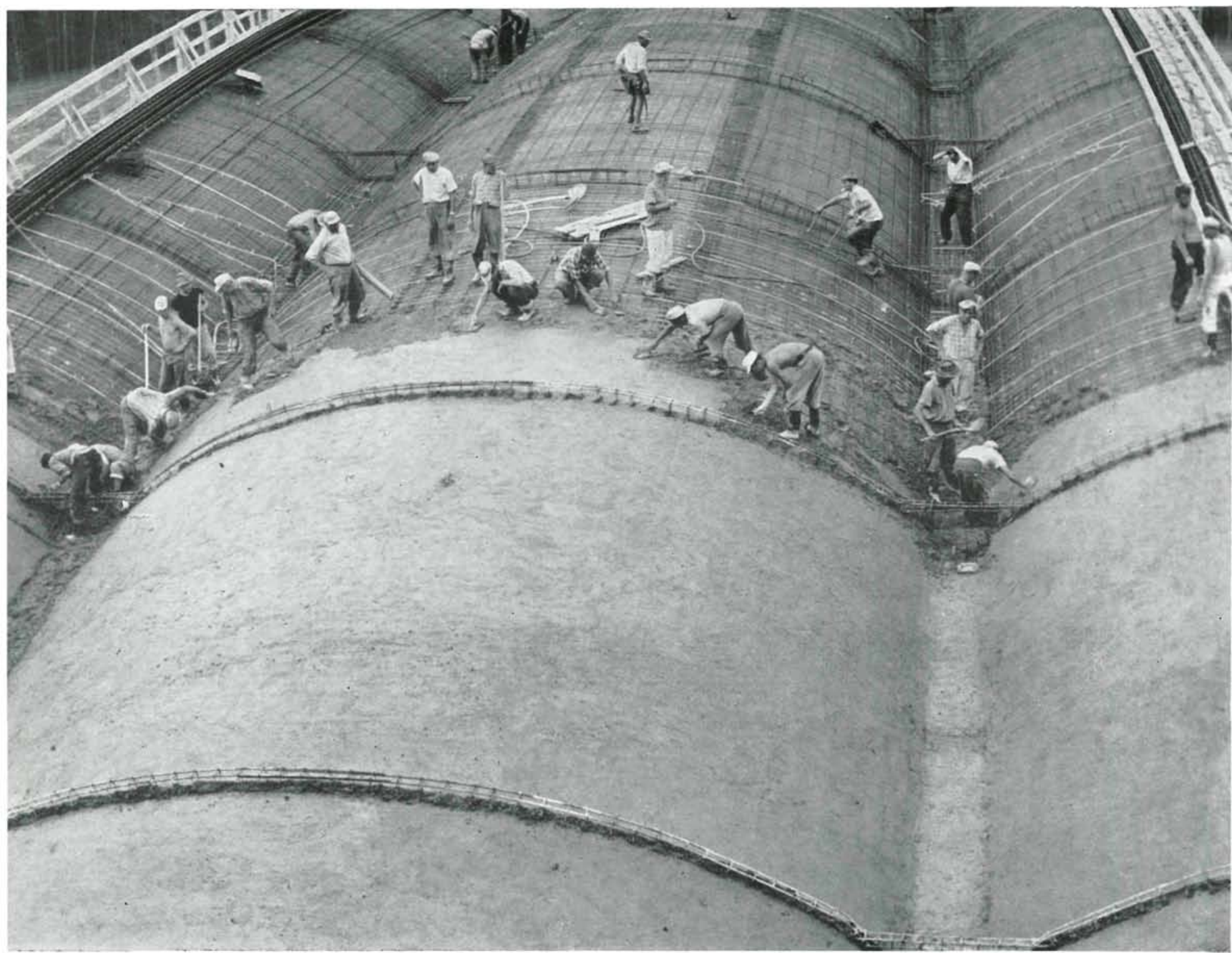


Tramo de nervios y lucernarios.

Primer tramo terminado e iniciación del segundo.

Ménsula en posición definitiva
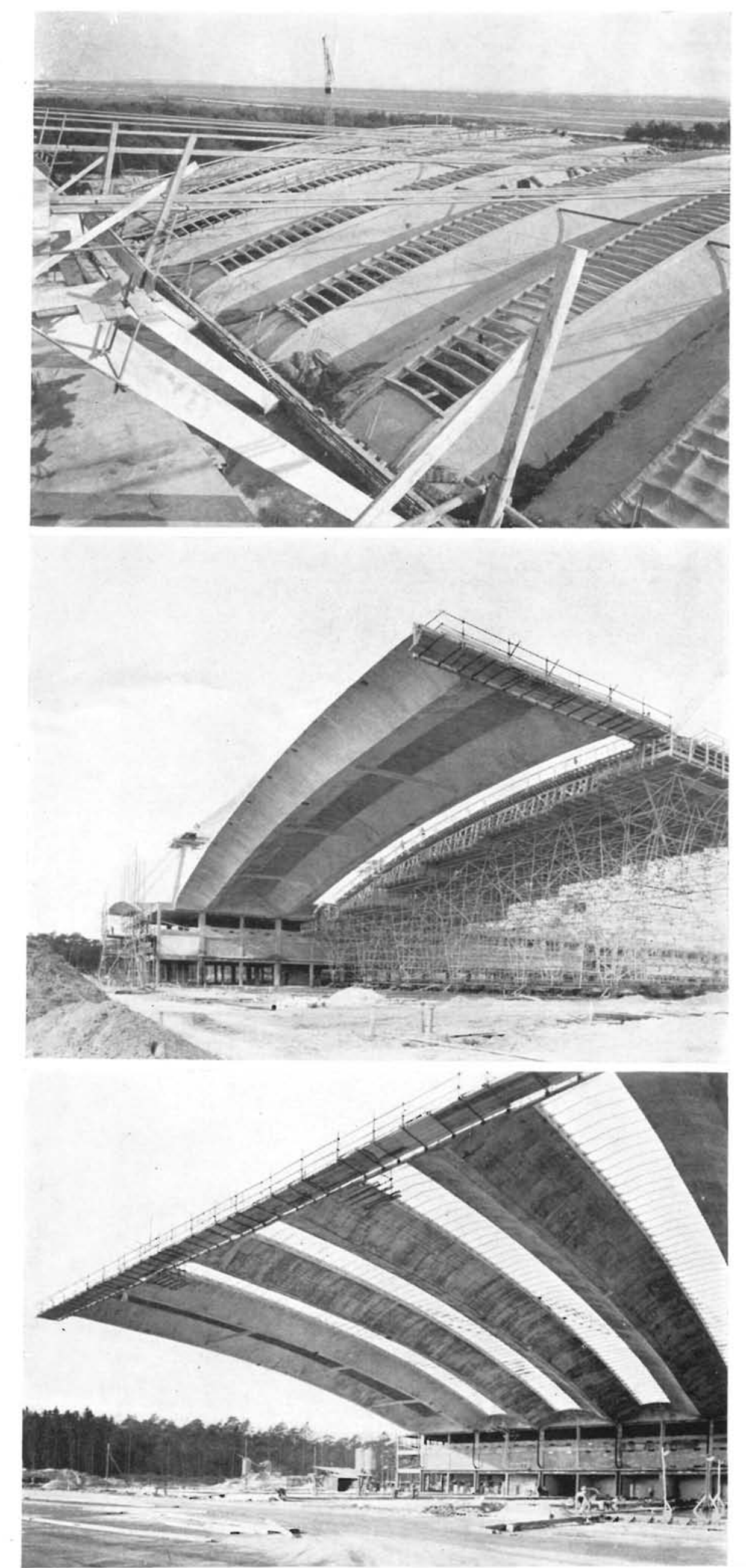

Las armaduras de los nervios de la cubierta están dispuestas formando un reticulado de barras que termina en los bordes en otra armadura zunchada constituyen. do viga; y en el vértice de la V que forman los nervios en su sección transversal, las armaduras se refuerzan con otras trans. versales que se extienden en toda la longitud del tramo. En el vértice propiamente dicho del nervio, las armaduras también cons. tituyen viga.

En el cuerpo central, de tres plantas, se han previsto sobrecargas de 500 a $1.000 \mathrm{~kg} / \mathrm{m}^{2}$, ya que en él se han instalado los talleres de reparación.

La pavimentación del suelo del hangar se ha realizado con un firme, de hormigón, de $30 \mathrm{~cm}$ de espesor. La dosificación de este hormigón fue de $320 \mathrm{~kg} / \mathrm{m}^{3}$; su resistencia, en probetas cúbicas, de $450 \mathrm{~kg} / \mathrm{cm}^{2}$, y la relación agua cemento, de 0,4 .

Se observó particular interés en el acabado del solado, ya que la superficie de rodadura tenía que caracterizarse por una gran resistencia al deslizamiento, teniendo en cuenta las manchas de grasa y otros lubricantes que dejan los aviones en el suelo. 

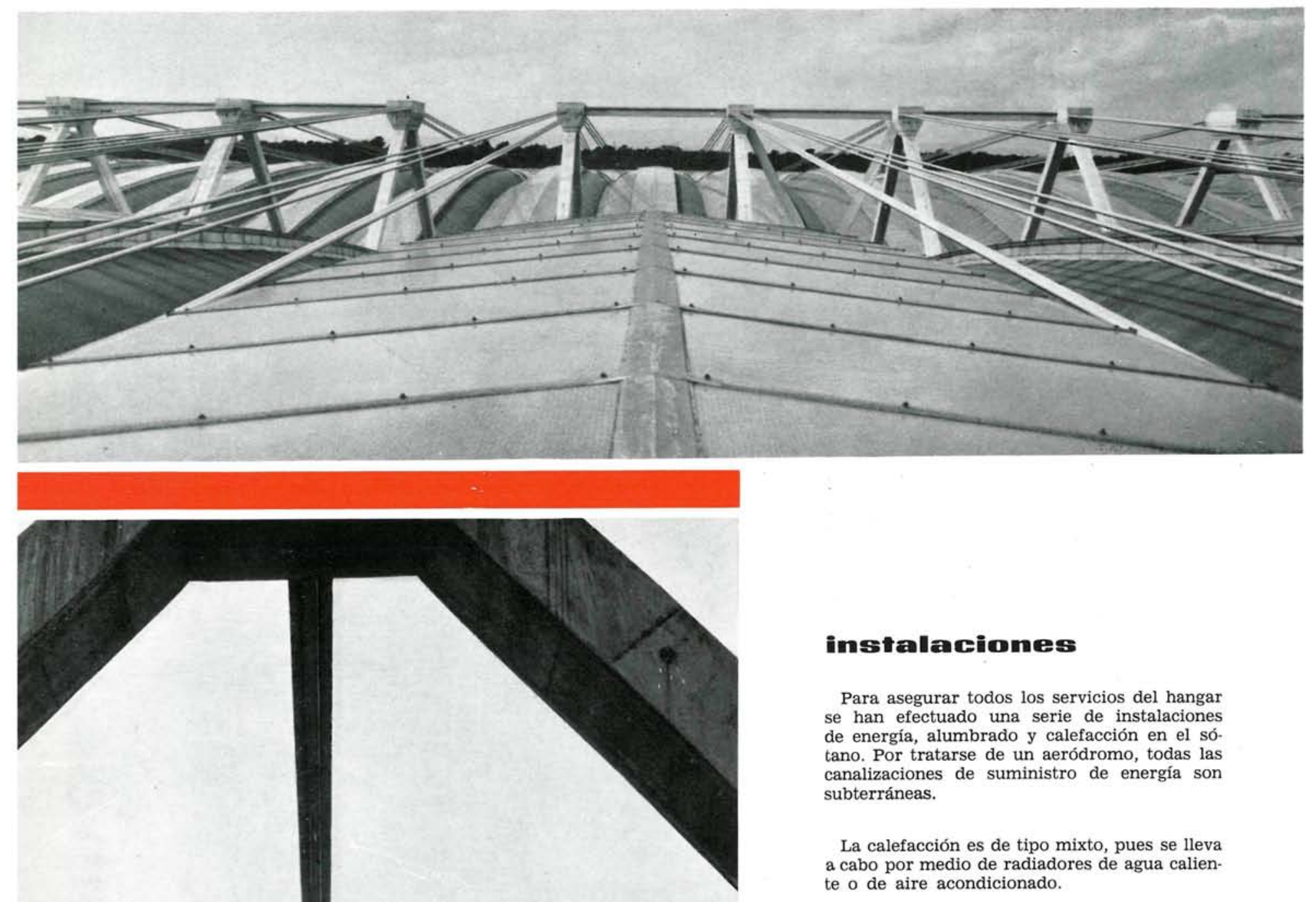

\section{instalaciomes}

Para asegurar todos los servicios del hangar se han efectuado una serie de instalaciones de energía, alumbrado y calefacción en el sótano. Por tratarse de un aeródromo, todas las canalizaciones de suministro de energía son subterráneas.

La calefacción es de tipo mixto, pues se lleva a cabo por medio de radiadores de agua caliente o de aire acondicionado.

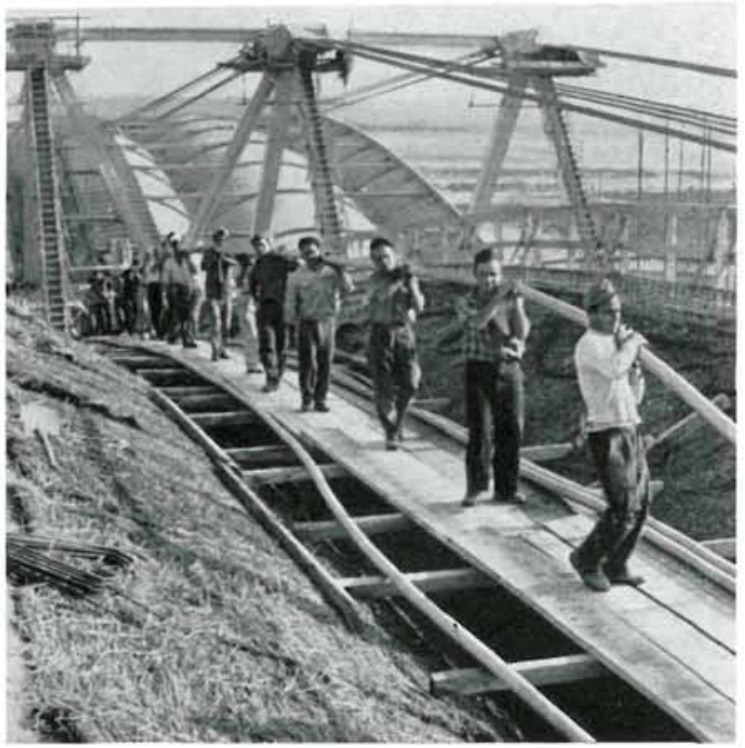




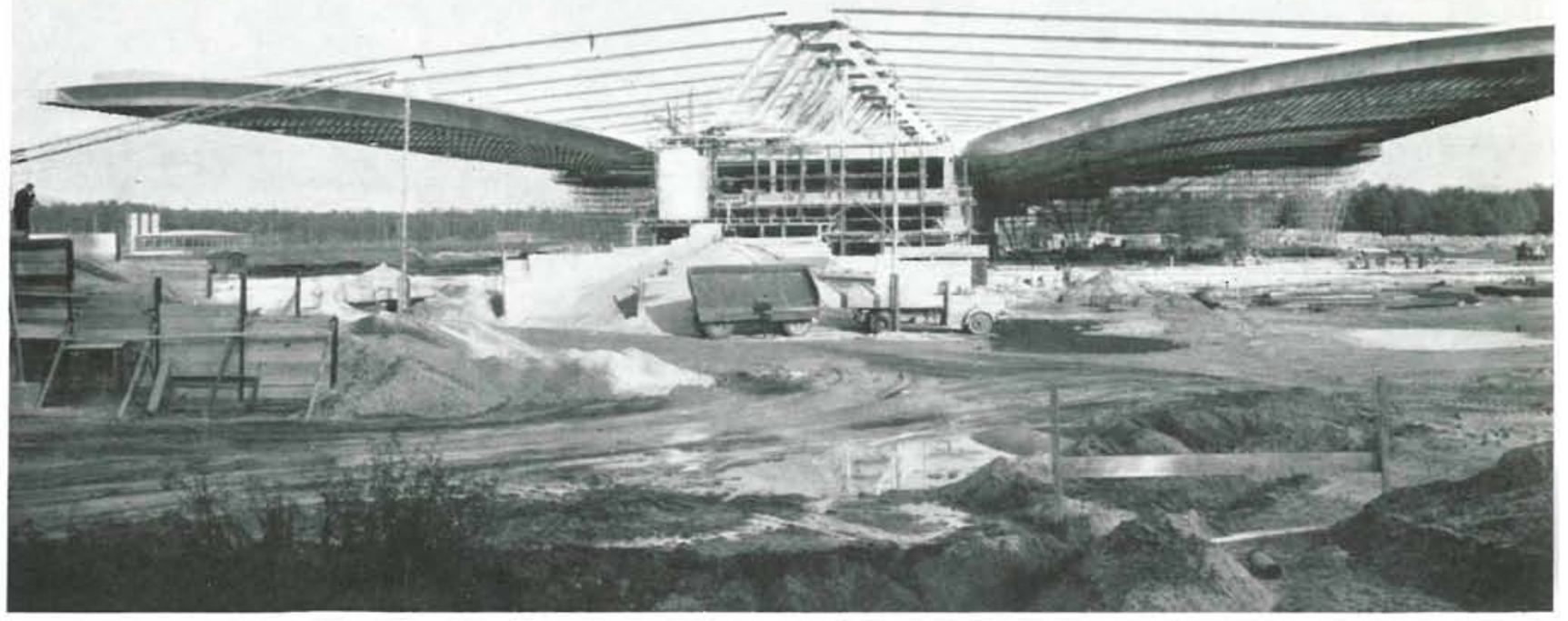

En las grandes naves del hangar, la parte más importante de la calefacción se hace a través del suelo.

La iluminación artificial se ha logrado por medio de tubos fluorescentes y lámparas de vapor de mercurio.

Como el interior del cuerpo central no tiene ventilación directa se instalaron ventiladores, los cuales expulsan al exterior, a través de la cubierta, el aire viciado de las distintas dependencias del hangar.

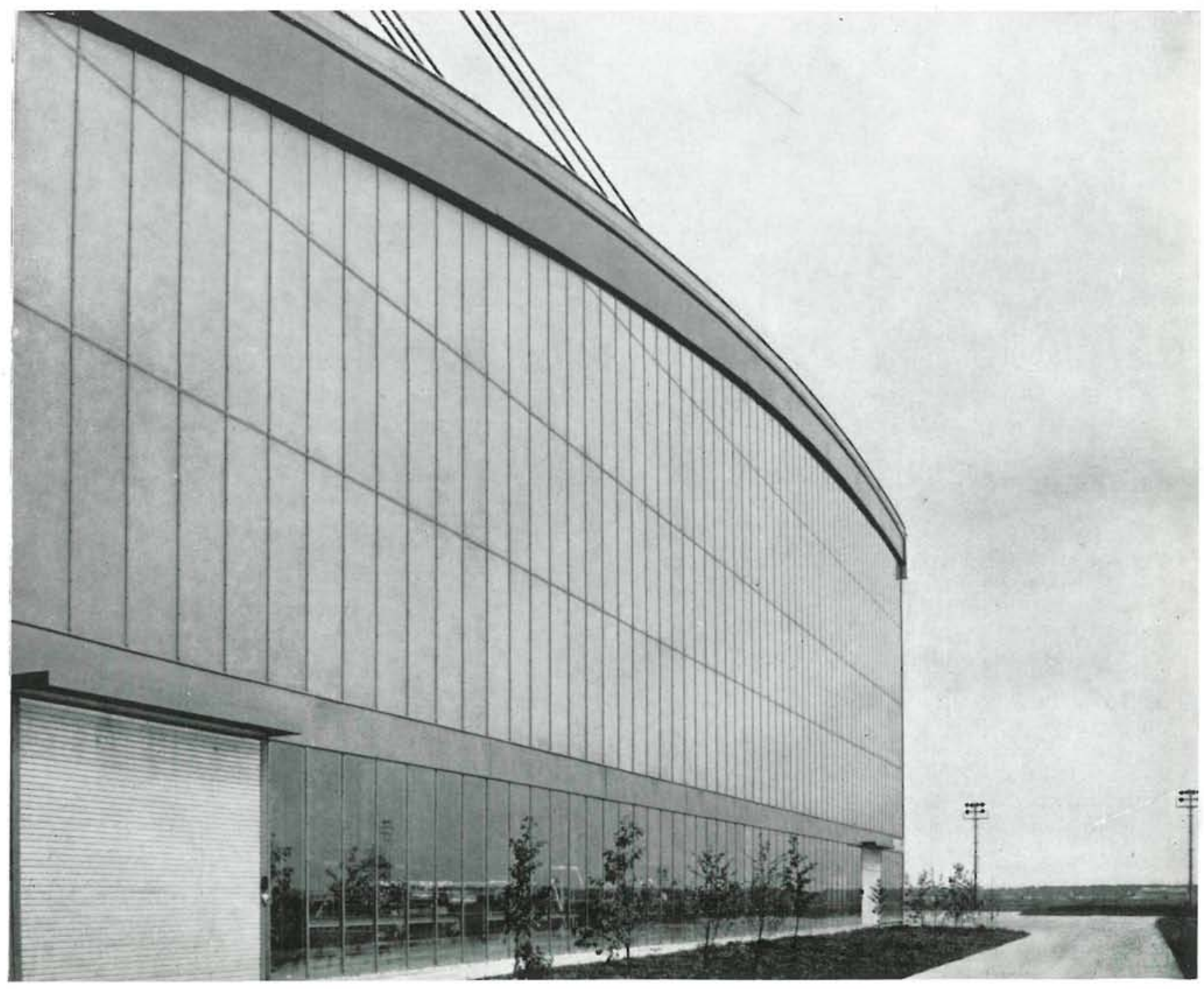


Para los servicios de reparación se han instalado grúas móviles en el interior del hangar, así como dispositivos corta-fuegos y contra incendios.

Los alrededores del hangar se han pavimentado con firmes de cesistencia similar a la prevista para las pistas de rodadura del aeropuerto. La superficie pavimentada es suficientemente amplia para permitir las pequeñas maniobras que los aviones han de realizar durante la entrada y salida del hangar.

La ejecución de las obras del hangar completo, con sus naves y cuerpo central, ha durado dos años, y se han llevado a cabo con plena satisfacción general y técnica.

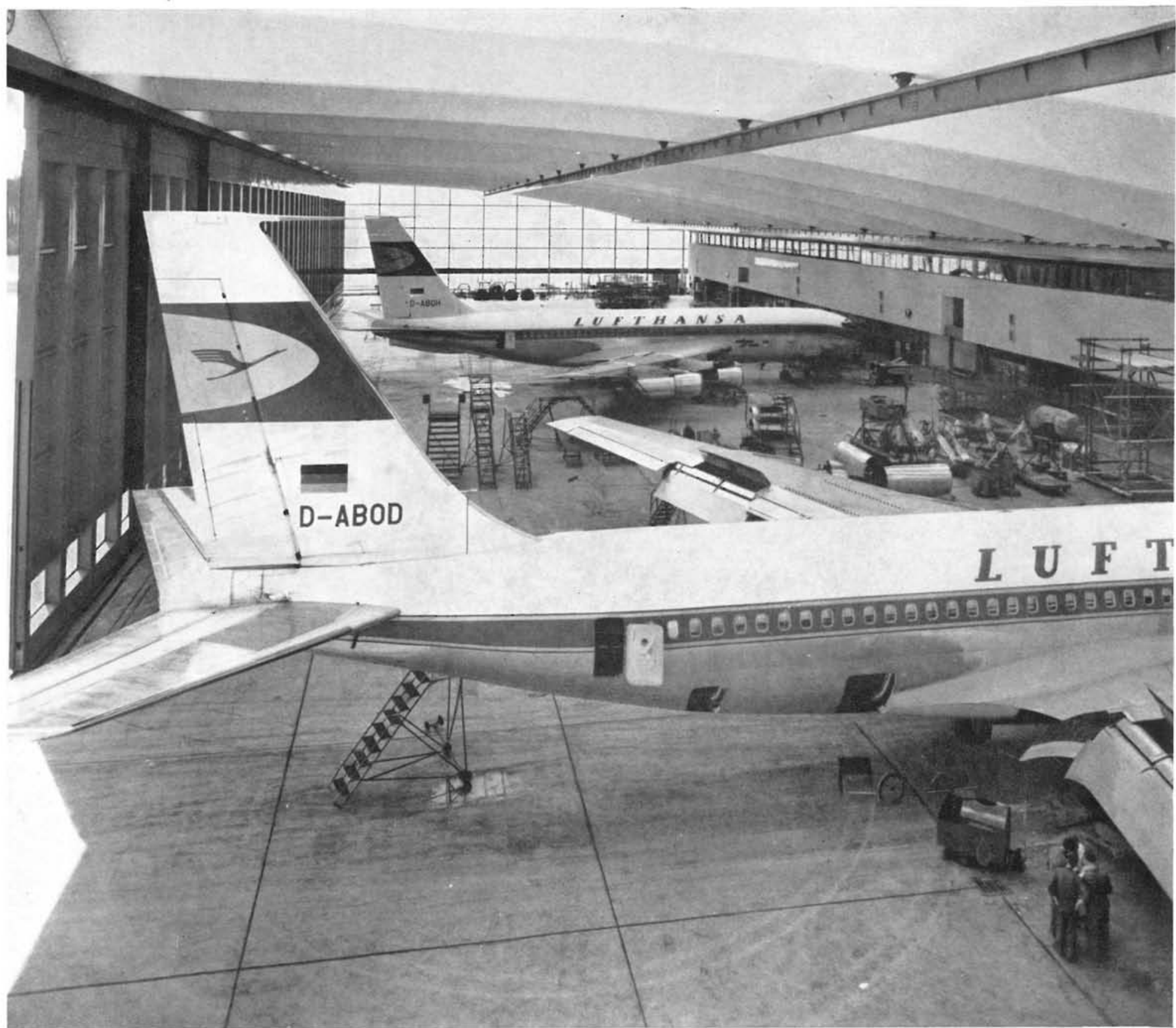

